\title{
Principles for organizing the architectural environment of arctic cities using the example of Vorkuta (Russia)
}

\author{
Daria Vabishchevich ${ }^{1, *}$, Igor Ivanov ${ }^{1}$, and Tamara Datsuk ${ }^{1}$ \\ ${ }^{1}$ State University of Architecture and Civil Engineering, 190005, St. Petersburg, Russia
}

\begin{abstract}
The paper discusses the principles for organizing the architectural environment of Arctic cities using the example of Vorkuta, (Russia). The subject of the study is the architectural environment of Vorkuta and the influence on its formation of various groups of factors climatic, psychological and environmental. Based on the study of the history of the appearance of the city and its condition today, the prospects of the region are assessed, and the main development vectors are identified. As a result of a comprehensive analysis of external factors and development prospects, the principles of organizing the architectural environment at different levels are formulated: urban planning level - the city and the quarter, architectural and planning level - the building. The principles of a possible organization of Vorkuta architectural environment are systematized, both in terms of impact levels and certain factors of influence, which are most significant for the region. The architectural environment of the city, created in the image of the cities of central Russia, was not adapted to the harsh northern climatic conditions. Studying the influence of various external factors on the urban environment will help formulating a conceptual scheme of the organization. In the future, it will prevent mistakes and contribute to the development of the city.
\end{abstract}

\section{Introduction}

The Arctic, the least studied region of Russia, occupies most of the country. The Arctic zone of Russia (Fig. 1) includes the territories of the Arctic and subarctic climate. The area covers $18 \%$ of the country's territory, which is about 3 million $\mathrm{km} 2$, including 2.2 million $\mathrm{km} 2$ of land, where about 2.4 million people live [1]. This is less than $2 \%$ of the population of Russia and about $40 \%$ of the total population of the entire Arctic. But despite the unknown and low degree of development, these territories have enormous development potential: minerals, energy, tourism, etc.

The current stage of development of science and society makes it possible to develop new resources. For Russia, the Arctic is an experimental site and an attractive region. The value of the Arctic territory, including access to the northern seas, the development of the mining industry, scientific and tourism potential, is reflected in the current State Program of

* Corresponding author: dashavab92@gmail.com 
the Russian Federation "Socio-economic development of the Arctic zone of the Russian Federation" [2].

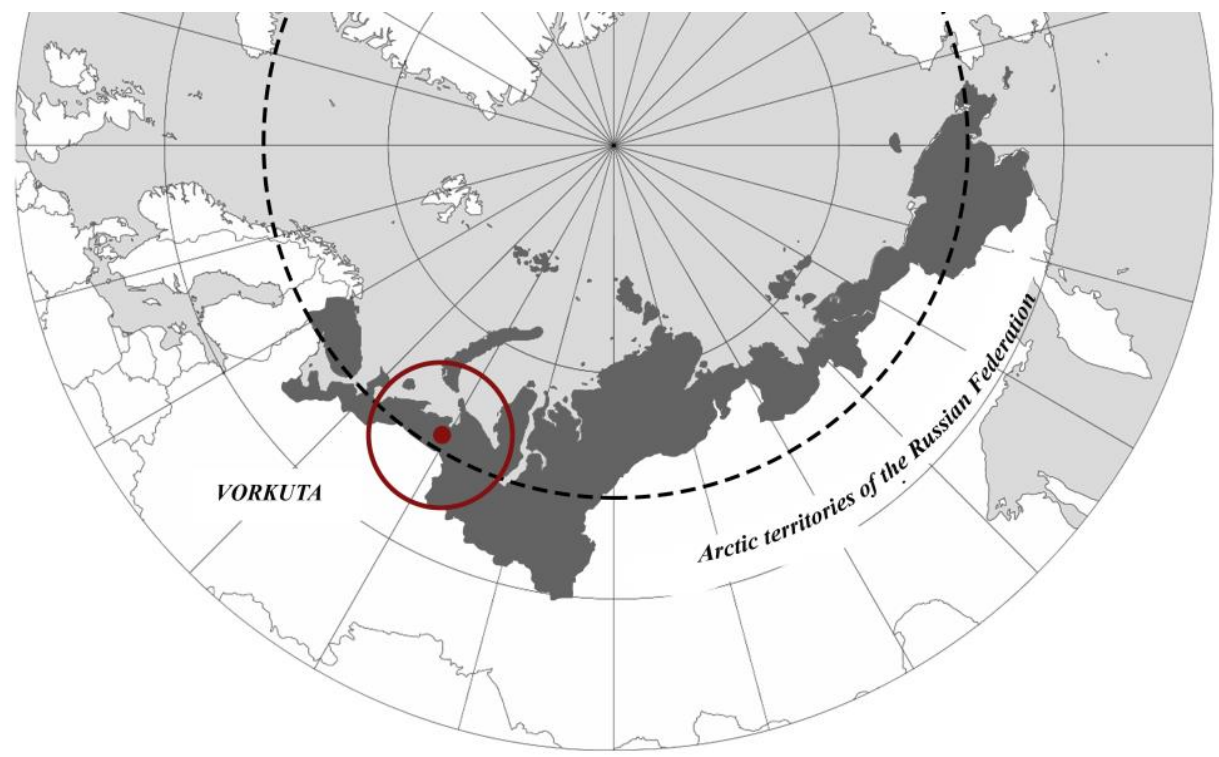

Fig. 1. Arctic territories of the Russian Federation.

\section{Materials and methods}

The organization of the architectural environment in Arctic cities is an issue that is increasingly attracting the attention of architects both in Russia and in other countries. Nowadays, cities in the Russian Arctic need updating and development. Given the new stage of development of the north and the scale of the region, the need for supporting cities with a permanent population becomes more acute for the integrated activities of all industries. At the same time, the existence of vanguard cities is a historical practice that accompanies activities in the region (for example, the cities of Salekhard and Katanga). This condition is necessary even for the organization of the shift method of temporary stay of people, taking into account the vast areas of the Arctic zone. In the context of forming a network of strongholds, Vorkuta - one of the Arctic vanguards of Russia - has great development prospects.

\section{Results and discussion}

\subsection{Current state of Vorkuta architectural environment}

The fast pace of development of the northern territories of the country began in the middle of the 20th century. Therefore, many modern cities originate precisely from the Soviet period. As a result, most of the buildings are typical panel buildings, as well as the remains of Stalinist classicism and dilapidated wooden residential buildings. All of them are poorly adapted for the harsh climate. Along with other social and economic problems, the problem of comfort of the urban environment is most acute for northern cities.

Extreme weather conditions, such as snowstorm, low temperatures, humidity, wind and others, are not only an obstacle to a comfortable life for people. In addition to the unique 
natural diversity, these features attract more and more tourists every year both from Russia and from abroad. In this regard, for the comprehensive development of the region, it is necessary to draw attention to the reconstruction of strongholds - cities.

Vorkuta is one of the vanguards of the Russian Arctic. The city is located in the north of the Komi Republic. Despite the remoteness from central Russia, it has good transport connection with the "big land" - air and railway communication. The city arose in the 1930s on the basis of coal mines. An important stage in the history is the work of the Gulag prisoners in the fields. The main feature of resettlement in the territories around the city was the system of workers' settlements in the places of coal mines, which formed the planning formation "Vorkuta Ring". The heyday of the city came in the late 1980s. But the crisis of the 1990s negatively affected both the coal mining industry in the region and the city, creating a threat to the cessation of production and the gradual resettlement of the city.

As a result of the mass outflow of the population from the city after the "perestroika", the villages of the Vorkuta Ring were almost completely abandoned. Today, the remaining small population lives in them, but the basic social infrastructure has been moved to Vorkuta. The administration also incurs large financial costs for the delivery of energy to these villages in the winter. For integrated and effective development of the Vorkuta region, a controlled urban economic compacting is proposed - the resettlement of the remaining population in Vorkuta and the creation of a compact northern city with a developed and functionally filled infrastructure. Moreover, there are reserve territories in the city - quarters of dilapidated housing, semi-settled houses, plots with demolished wooden barracks. Thus, having the need to develop these territories, the city of Vorkuta has enormous potential for an experimental site for organizing the architectural environment in the Arctic region.

Nevertheless, in 2014, as part of the Strategy for the socio-economic development of the Vorkuta municipal district for the period until 2020, a plan for the transformation and new direction of the city's life was developed. This became the reason for drawing attention to the situation in the city not only of local authorities, but also of architects and urban planners from all over Russia, and in particular, students and teachers of St. Petersburg State University of Architecture and Civil Engineering. Today, Vorkuta continues to decrease population. Therefore, the problem of transforming urban areas, the formation of a new approach to development is now particularly acute. The city needs to build new modern residential buildings and create a comfortable environment. The villages of the Vorkuta Ring are almost completely abandoned, the remaining small population must be resettled in Vorkuta, and a compact northern city with developed and functionally full infrastructure is created (Fig. 2. a, b). This is being implemented according to the Comprehensive Program "Optimization of the urban and economic development of the city of Vorkuta and the Vorkuta Region" developed by the administration of the municipal entity of the Vorkuta City District. 


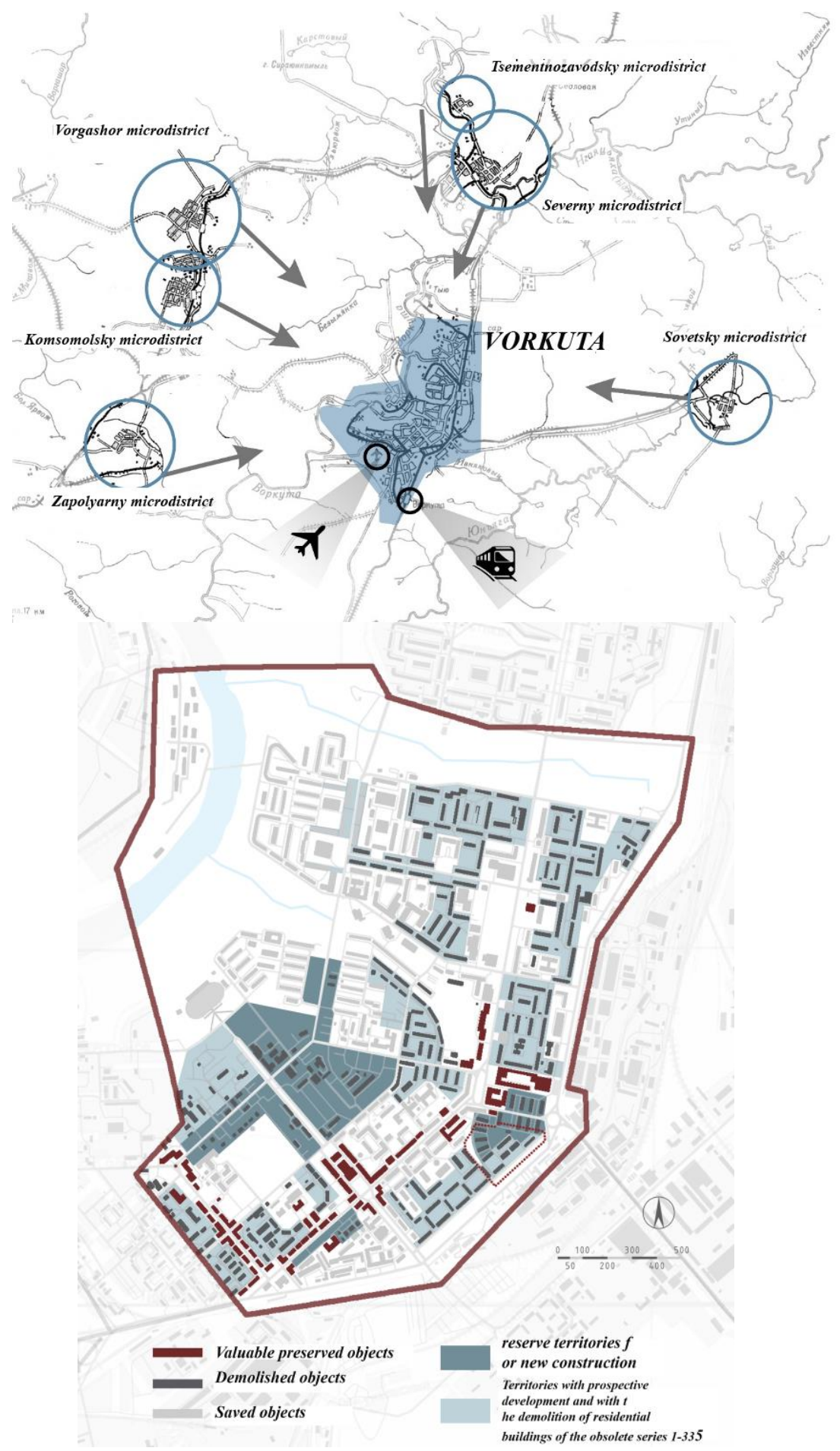

Fig. 2. a) The plan of resettlement of residents of the "Vorkuta Ring"; b) The layout of the reserve territories for housing under the program "Optimization of the urban and economic development of the city of Vorkuta and the Vorkuta region". 


\subsection{Factors affecting the architectural and planning solutions of the architectural environment of Arctic cities}

The development of a conceptual scheme for the organization of the architectural environment of Arctic cities using the example of Vorkuta contributes not only to the formation of the city as a stronghold for the development of the Arctic, but also to replenishment of the knowledge base and architectural design in severe climatic conditions of other cities.

The choice of architectural and planning solutions in the region is influenced by several groups of factors.

1. Natural and climatic. This group of factors is most important when designing in the Arctic. The Vorkuta urban district is located in the IG construction and climatic subarea, this creates a certain specificity. Along with common features of the Arctic region, such as low temperatures, permafrost, a short warm season, polar night and day, and a minimum of vegetation, the most significant is the snowstorm accompanying the wind blowing mainly from the south in winter. This factor affects both the urban and the space-planning component of the facilities.

The presence of permafrost, difficult geological conditions affect the placement of buildings, structure and number of storeys. They require accurate geological forecasts of soil changes, as well as the flexibility of solutions to changing environmental conditions.

2. Psychology and emotional environment. Difficult climatic conditions directly affect the emotional state of people. The polar night, when the time of day is not distinguishable for several months, and the color perception of the environment by the human eye worsens, causes the need for special architectural solutions. At the same time, the desolation and decay of the city, whose population has decreased by more than 3 times over 10 years, also worsens the appearance of the environment. Many areas of Vorkuta and satellite villages are partially abandoned; resettled houses are often found among residential buildings. The Rudnik district, from where the city began, is completely abandoned. Residents watch these buildings daily from the windows of their houses, passing along the street. Empty areas appear in the urban environment, which must be replenished to feel a compact city. Spring, when light appears in the city, but there is still snow, is the season of the monochrome environment. When a person needs spring diversity, he sees a solid white landscape. This creates a problem of monotony of the environment. The lack of a developed leisure system and public spaces in Vorkuta restrains the development of society, a change in the attitude of residents and guests to the city.

3. Ecology in the Arctic. Disturbed by rather abrupt introduction of man in the 20th century, the natural and landscape environment of the region currently needs careful attention and protection on the part of man. The Polar Urals represents the oldest mountain ranges. Their silhouette and landscape, as a non-renewable natural resource, must be preserved. Constructive and space-planning decisions are primarily affected by these factors.

Thus, the concept of the organization of the architectural environment of Arctic cities using the example of Vorkuta includes several levels: urban planning - the city and quarter, space-planning and architectural-compositional - the building.

\subsection{Optimization of the urban environment. Urban planning level of organization}

At the urban level - on a city scale - one of the signs is the presence of a direct street grid. In Vorkuta, where there is a chance of snowstorm and a large amount of snow falls in winter, this is most relevant. The location of streets and buildings parallel to the prevailing 
winds contributes to blowing snow and simplifying the cleaning system. The same principle is used at the quarter level. At the same time, reservation of snow accumulation places after cleaning will allow having natural barriers to wind in winter, protecting pedestrian paths (Fig. 3). Reducing snow cover and thus reducing labor costs for snow removal is an important aspect of the formation of a new environment.
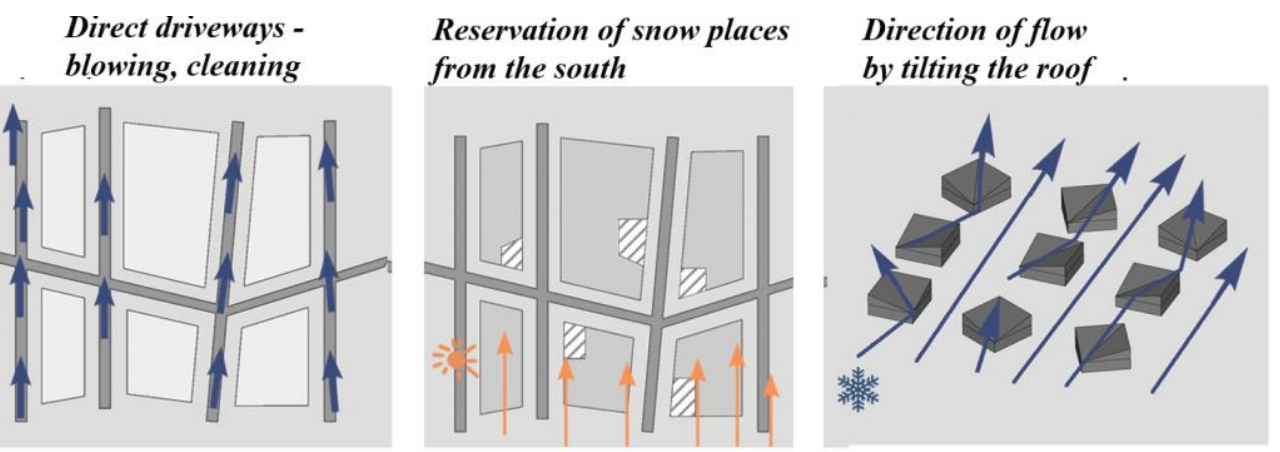

Multislope roof, slope to the wind (wind / snowstorm --- snow accumulation)

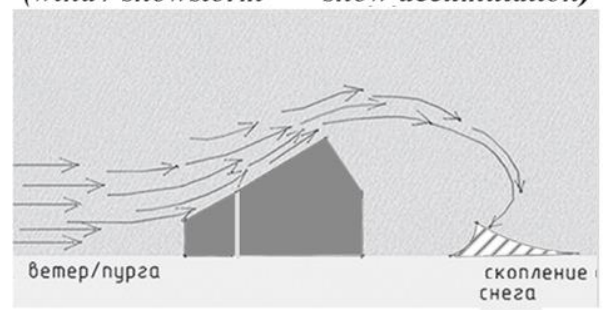

Yard open to the wind

Entrance from the yard
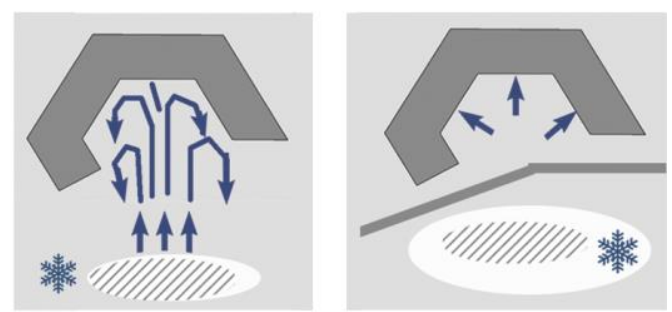

Fig. 3. Ways to minimize snow cover at the city and quarter level.

At the quarter level, you can use the following techniques. Modern computer software allows creating quarter models and testing various loads. A preliminary study of the quarter on the movement of snow masses and wind will suggest the most correct location of buildings and their configuration. One of the tricks is the direction of wind and snow flows using the roof and the shape of the building. For example, in his project "A house of a new type for miners in Vorkuta", A. Shipkov proposes opening a yard to the south, to the wind. This will create flows that blow snow from the yard. In addition, the accumulation of energy, the opening of the building to the south, the use of different color solutions will turn the quarter into a vibrant diverse environment. Also, at the quarter level, it is possible to use the seasonal forecasting method, dividing walking routes into winter and summer ones.

\subsection{Consideration of building requirements in the Arctic (consideration at the level of space-planning solutions of buildings)}

Finally, at the building level, all previous schemes and smaller ones are taken into account. The location of the building, its structural system is completely dependent on geology and temperature. Low temperatures mainly affect the spatial solution of a building (Fig. 4), as well as building materials. The main idea of all solutions is, on the one hand, to reduce the area of external building envelopes, and on the other, to fill the building with various functions to the maximum. 


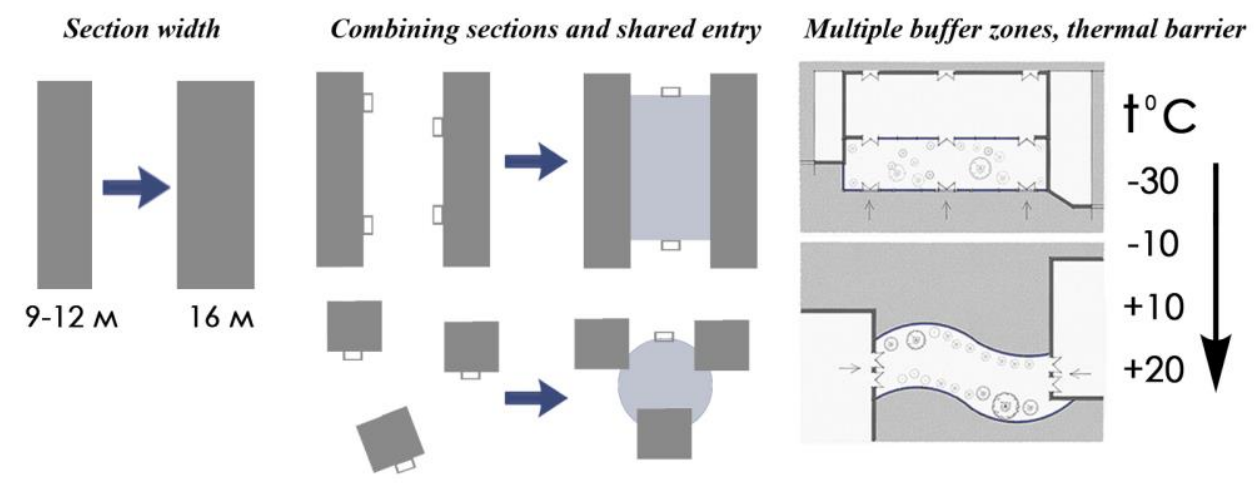

Compactness, functionality

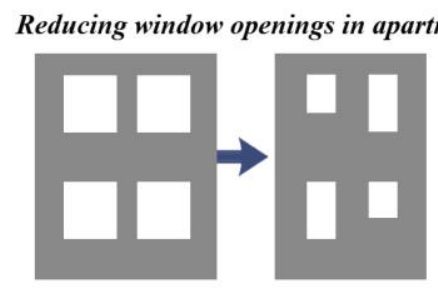

Balconies in the wall plane
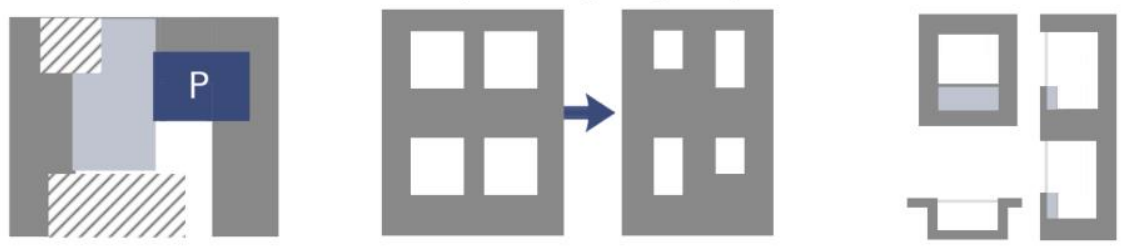

Fig. 4. The effect of low ambient temperatures on the formation of buildings.

Buildings with supports are used not only at scientific stations, but also in the city. This minimizes the footprint from the building, as well as ensures the ventilation of the foundation and, as a result, helps to preserve permafrost. Increasing the width of the section prevents freezing. The presence of a system of vestibules and buffer spaces limits the loss of heat and, consequently, energy costs. Also, the introduction of atriums and public spaces for communication and leisure as part of administrative and residential buildings expands the ability of people to communicate with each other.

In addition, the use of alternative energy sources, energy storage during the polar day can also be incorporated into architectural solutions (Fig. 5).

Permafrost conservation

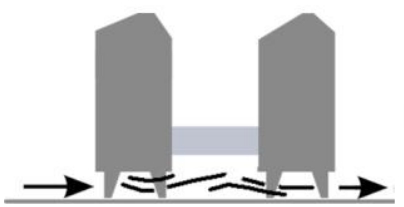

Energy storage

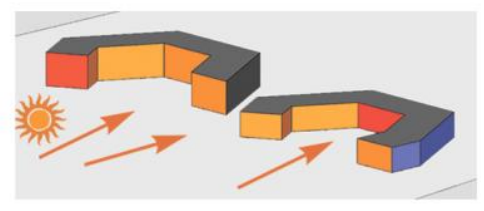

Landscape conservation

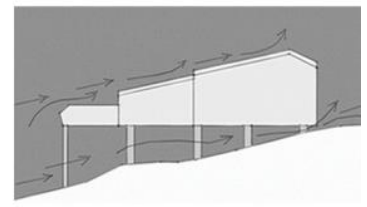

Fig. 5. The influence of environmental factors on the formation of buildings.

The functionality of residential and public complexes allows reducing movement in a cold city in winter. Given the polar night, when there is no daylight, and the polar day, when it is in abundance, it is possible to reduce window openings in living rooms to reduce heat loss. But at the same time, this is compensated for by translucent atriums and tambours, since the temperature can be lower in these rooms and their main function is to protect against external factors. In the exterior of the building, the fundamental approach for the Arctic city is reflected in the application of environmental diversity methods. Limitations of spatial solutions, such as the most streamlined shapes and minimization of enclosing structures, can be compensated for with a color scheme and different heights. 
Combining various types of buildings, height, decoration, color scheme, as well as the inclusion of translucent inserts that replace color in architecture in the dark, it is possible to achieve a diverse and comfortable silhouette of the street. Also, there is a way to use illumination in the dark, highlighting the contours of buildings and facades. This technique is currently used in many northern cities, including Vorkuta. The introduction of diversity in the solution of the environment, both color and functional ones, will improve the quality of life in the city (Fig. 6).

\section{Street silhouette}

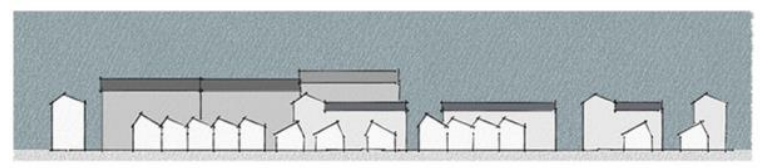

Color palette

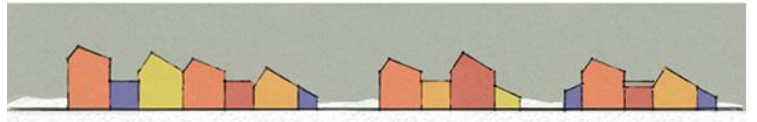

Street lighting

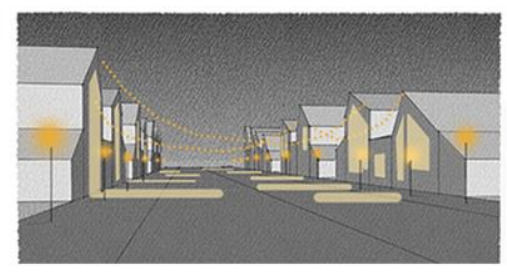

Fig. 6. The influence of psychological factors on the formation of buildings.

\section{Conclusion}

Nowadays, the problem of reconstruction of the vanguards of the Russian Arctic is relevant and requires attention. The development of the region is impossible without an integrated approach. In the future, existing cities may become important starting points for the development of both the energy and tourism wealth of the Arctic. Therefore, it is necessary to formulate principles for organizing a comfortable environment in Arctic cities.

\section{References}

1. URL: https://tass.ru/info/6312329

2. URL: http://government.ru/rugovclassifier/830/events/

3. B.M. Poluy (1989)

4. P.Collymore (1982)

5. E. Kalemeneva, J.Qu.Russ., 5, 1, 153-170 (2017)

6. M. Jull, J.Arch.Ed., 70, 2, 214-222 (2016)

7. M. A. Steane \& K. Steemers (2004)

8. W. McDonough (2002) 